\title{
Hurricane Preparedness for Forage Crops in the Southeast United States ${ }^{1}$
}

\author{
José C. B. Dubeux, Jr. and Edward K. Twidwell ${ }^{2}$
}

This guidance is applicable to the following state(s)/ region(s):

- Southeast United States with more emphasis on the Florida peninsula and Gulf Coast

\section{This section will focus on:}

- Preparing forage crops, conserved forage, and grazing areas for potential hurricane damage

- Alleviating hurricane damage on forage crops and grazing lands-the aftermath

\section{Pre-Hurricane Planning and Preparedness \\ Initial Site Planning}

- Plan which forage crops should be planted according to the specific ecological conditions within the farm. Areas prone to temporary waterlogging conditions due to storms should be planted with forage species tolerant to these conditions. Limpograss (Hemarthria altissima) is an example of a forage species tolerant to temporary flooding that is adapted well to south-central Florida and along the Gulf Coast.

- Areas susceptible to saltwater intrusion should be planted with more salt-tolerant forage crops. Bermudagrass (Cynodon dactylon) could be an option. Bermudagrass, however, will not tolerate long periods of flooding. Tolerance to salinity is also moderate to low, but previous experience in Louisiana indicates that bermudagrass will survive after storm surge and saltwater intrusion.

- Conserved forages (i.e., hay, haylage, silage) must be kept on higher ground to avoid flooding. Hay should be stored in a hay barn.

\section{Site Establishment}

- During the site establishment and design, pastures should be separated from forested areas. Scattered trees on the pastures are important, but areas densely populated with trees should be avoided, especially during the hurricane. Falling trees can cause accidents, killing livestock during the storm. However, allowing livestock into hammocks does provide some cover for the animals.

- Design an internal paddock in a higher-elevation area near the hay barn or feeding facility with access to drinking water. External fences are usually damaged during hurricanes. A smaller area makes it easier to repair the exterior fences and allow cattle feeding during the storm, which is important to prevent cattle from leaving the property. Make sure you have a generator if you are pumping water from a well.

1. This document is SS-AGR-439, one of a series of the Agronomy Department, UF/IFAS Extension. Original publication date November 2019. Visit the EDIS website at https://edis.ifas.ufl.edu for the currently supported version of this publication.

2. José C. B. Dubeux, Jr., associate professor, Agronomy Department, UF/IFAS North Florida Research and Education Center; and Edward K. Twidwell, professor, School of Plant, Environmental and Soil Sciences, Louisiana State University AgCenter; UF/IFAS Extension, Gainesville, FL 32611.

The Institute of Food and Agricultural Sciences (IFAS) is an Equal Opportunity Institution authorized to provide research, educational information and other services

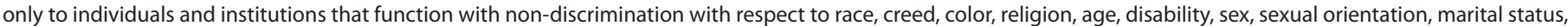

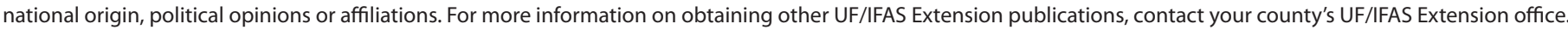
U.S. Department of Agriculture, UF/IFAS Extension Service, University of Florida, IFAS, Florida A \& M University Cooperative Extension Program, and Boards of County Commissioners Cooperating. Nick T. Place, dean for UF/IFAS Extension. 


\section{Seasonal Considerations Outside of}

\section{Hurricane Season}

- Before the hurricane season begins, make sure the generators for pumping water from wells are working properly.

- Consider strategic tree pruning to reduce damage to forage storing facilities and equipment barns.

- Keep the fence lines with as few trees as possible. Trees are the major cause of damage to fence lines.

- Make sure you have enough stored forage (e.g., hay, baleage). You may need to use a large amount of it during the hurricane season because the fences may be damaged, and you may need to keep the cattle confined in a smaller area.

\section{Monthly Considerations during Hurricane Season}

- Make sure you have enough forage mass in the grazing lands and stored forage during this season. Resources (hay, feed, fuel, etc.) may be limited during and after an extreme weather event.

- Check the stock of inputs you typically use and store the most important ones such as fuel and feed. Make sure you have a reliable water supply. During a hurricane, these supplies may not be available to buy.

\section{Annual Considerations}

- Develop guidelines and train personnel with a systematic procedure for securing livestock, reducing damages to facilities, and preserving feedstock by assigning individual responsibilities in case a hurricane hits the property.

- Conduct annual training with personnel addressing the standard operational procedures in case a hurricane hits the farm.

- Update insurance policies for equipment and facilities prior to the beginning of the hurricane season.

\section{When a Hurricane Is Forecast to Impact Your Area (1 to 7 Days Before)}

- Fuel vehicles and equipment and try to store sufficient fuel in appropriate containers.

- Inspect the fence lines and prune trees that are endangering facilities and fence lines.

- If weather permits, harvest and conserve forage crops that might be helpful to feed animals during the storm.
- If crops are in an area that will likely experience total loss due to flooding, harvest ahead of time and try to conserve them as hay. If conserving the forage is not practical, consider putting the animals to graze it before total loss from a hurricane occurs.

- Test all generators and wells.

- Put hay bales and equipment on higher ground to reduce risk of flooding.

- If possible, store irrigation equipment in a safe place.

- Artificial shade structures must be tightened up to minimize wind destruction and further destruction of fence lines. If possible, remove shade cloth to minimize damage to or complete loss of the shade structures.

\section{One Day Before a Hurricane Is Forecast to Impact Your Area}

- Connect generators with water pumps and essential buildings.

- Disconnect electrical power to all buildings that may be subject to flooding.

- Move cattle away from forested areas. Keep them in the inner paddock. Make sure they have enough hay and access to water.

\section{Post-Hurricane Recovery} Immediately After the Hurricane Has Passed

- Take an inventory of the livestock herd and identify any missing or injured animals. Leave livestock in the inner portion of the farm and ensure they have enough forage, fresh water, minerals, and shade.

- Downed and damaged fences are likely after a hurricane. It is important to restore some type of temporary fencing as soon as possible in order to keep livestock contained. Start rebuilding perimeter fences.

- Watch for downed power lines, debris, and other hazards.

- Examine pastures and hayfields and remove dangerous debris, such as strands of barbed wire, chemical bottles, insulation, and trees.

- Certain tree species can cause diseases in livestock that consume their leaves or nuts. These include buckeye, wild cherry, and oak. Make sure that livestock do not have access to downed trees of these species.

- Livestock must have an adequate supply of fresh water to survive. Water consumption needs are particularly high during hot weather conditions. 
- Make sure livestock have access to forage or other sources of feed as well as free-choice mineral supplements.

- Monitor pastures and hayfields for the duration of flooded conditions.

- Document damage with photographs to assist with insurance recovery.

\section{Within a Month After Hurricane Impacts FLOODING CONCERNS IN PASTURES}

Hurricanes have the potential to bring large amounts of precipitation to certain areas or regions in a short amount of time. Flood damage to pastures can vary depending on several factors, such as time of year, temperature, soil texture, flood duration, and water movement. Flood events lasting one day or less usually have low impact on plant survival. Damage to plants is usually less in areas of moving water compared to standing, stagnant water. Deposition of debris on leaves and crowns in standing water increases injury. Damage from flooding is reduced if the plants are not completely submerged. Plant damage usually increases with longer periods of water submersion. Plant species that have good potential to survive short flooding periods include bermudagrass, bahiagrass, dallisgrass, switchgrass, and eastern gamagrass. The pasture plants that typically have low chances of surviving extended flood damage are small grains, annual ryegrass, and most forage legumes. Tall fescue has a moderate potential to survive flooding, as long as water submersion lasts no longer than one or two days. Severely damaged stands may require more time for recovery. Full recovery can be achieved with proper weed control, proper soil fertility, and deferred grazing.

\section{DAMAGE TO HAY}

Producers should assess their hay resources as soon as it is safe to do so. Hay that has been stored in flooded areas might have contamination from mold and yeast as well as a significant decrease in nutritive value. The amount of decay, mold, and possible other contaminants in flooded hay greatly reduces its value and makes it potentially hazardous to feed to livestock (Figure 1). Hay that was stored in flooded barns should be removed as soon as possible because it will start to heat up, making spontaneous combustion possible. Any hay that was severely damaged by flooding and determined unsuitable for feeding should be disposed of by burning or composting. Avoid feeding moldy hay, as this may cause illness or decreases in animal production and reproductive fertility to occur. One option is to test the hay for mycotoxins and make a decision whether to feed or not based on the test results.

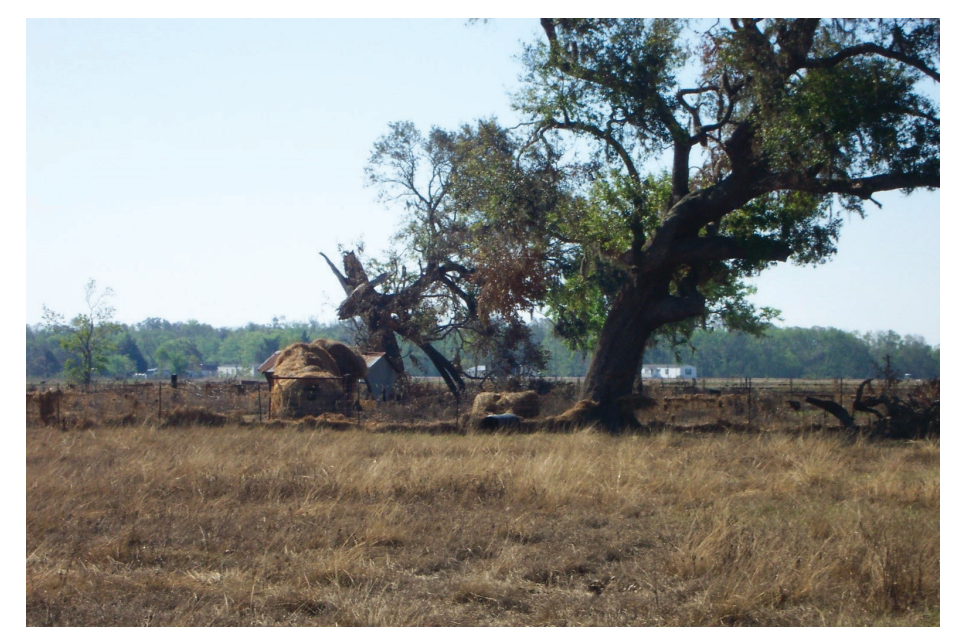

Figure 1. Damage to trees and hay caused by Hurricane Rita in late September of 2005.

Credits: Edward Twidwell, LSU AgCenter

\section{SALTWATER INTRUSION CONCERNS}

Flooding during hurricanes can occur via heavy rainfall and/or seawater brought onto land by high winds. Flooding of pastures with seawater can cause salt buildup in soils, which reduces forage growth. The capacity of forage plants to grow satisfactorily in saline conditions depends on several interrelated factors, including physiological condition, growth stage, and rooting habits. Plants absorb essential plant nutrients in the form of soluble salts, but excessive accumulation of soluble salts (soil salinity) suppresses plant growth. When soil salinity exceeds a plant's tolerance, growth declines (Figure 2). Reduced growth caused by salinity is a progressive condition that increases as the salinity rises above a plant's tolerance threshold. Producers can determine the salt content of their soils by taking soil samples and then sending them to a public or private soil testing laboratory. If a laboratory is not available, producers can perform a simple experiment (bioassay) on their own with a small amount of soil from affected areas before planting large acreages of forage crops. Take soil samples in the top 3 inches from several locations in the field suspected of having high salt content. Mix the soil samples together in a clean plastic pail. Take the soil and place it into smaller containers, such as boxes, milk cartons, or cottage cheese containers. Sprinkle a small amount of seed (about a teaspoon) into each container of soil and cover the seeds with about $1 / 2$ inch of soil. Wet the soil with water, but do not saturate it. Within 7 to 10 days after planting, injury symptoms should become apparent. Possible symptoms include no germination, partial germination, slowed emergence, or dried-out appearance of seedlings. Although this is not a precise experiment, it should provide an idea of how various forage species may germinate and grow in areas affected by saltwater intrusion. Producers can then take information obtained from this bioassay to make 
decisions relative to planting small to large acreages of winter annual forage crops.

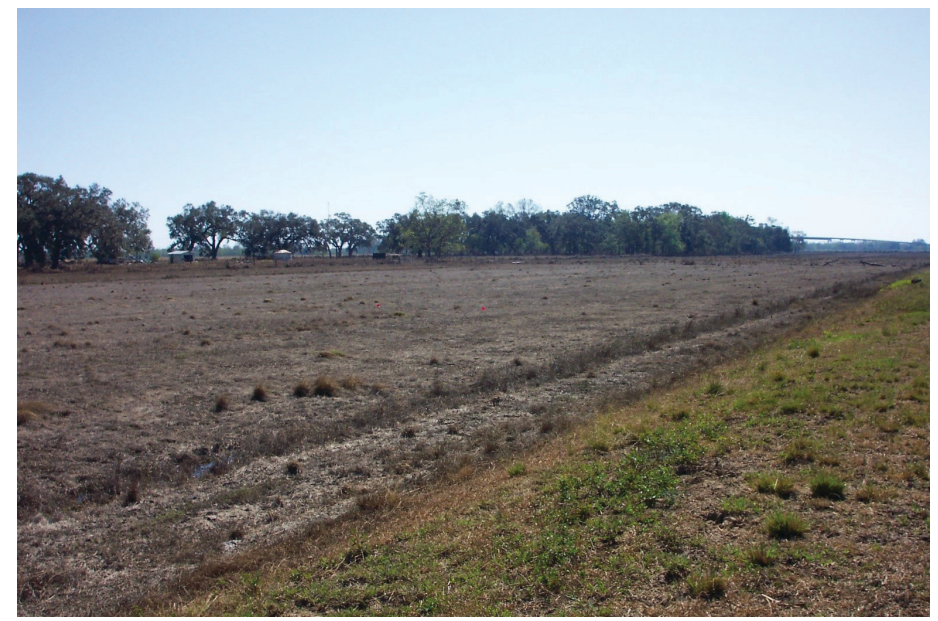

Figure 2. Damage to perennial pasture due to saltwater intrusion immediately following Hurricane Rita in late September of 2005. Credits: Edward Twidwell, LSU AgCenter

Pasture plants commonly grown in the Southeast vary in their tolerance to salty conditions. Bermudagrass is generally considered to have a high salt tolerance. Some research indicates that bermudagrass can tolerate salt concentrations of up to 5,000 parts per million (ppm) for extended periods (Miyamoto 2008). Other perennial forage species such as bahiagrass and carpetgrass are not as salt-tolerant, but in relative terms, they are still considered salt-tolerant. Most cool-season forage species, such as tall fescue, annual ryegrass, wheat, and barley, are considered moderately tolerant to salty conditions. Most clover species, including white, red, arrowleaf, and crimson, are considered salt-sensitive. The rate of recovery of pasture plants after saltwater intrusion is dependent upon the speed at which the salts can be leached out of the root zone (0-6 inches of the soil). Rainfall is a major factor in reducing salinity because it leaches the salts from the soil. In fact, 5 inches of rainfall will remove about $50 \%$ of the soil salts. Therefore, frequent rainfall events in the weeks and months after a hurricane will help to expedite pasture recovery.

Soil salinity is a major concern when attempting to plant winter annuals such as ryegrass during the fall months into areas that have experienced some level of saltwater intrusion. In general, forage seedlings are much more susceptible to salt injury than mature plants. The salinity threshold for seedling ryegrass is $1,800 \mathrm{ppm}$. In some instances, it is worth trying to seed annual ryegrass because that might be the only source of forage for the cool season right after a hurricane, even considering the decrease in productivity due to salinity and reduced germination.

\section{Reference}

Miyamoto, S. 2008. "Salt tolerance of landscape plants common to the Southwest." TR-316. Texas Agrilife Research Center at El Paso. https://agrilifecdn.tamu.edu/elpaso/ files/2011/TR-316-FINAL-TOLERANCE-REPORT_updated.pdf 